\title{
ARE WE JUSTIFIED IN SUPPLEMENTING ELASTOGRAPHY WITH HIGH RESOLUTION ULTRASONOGRAPHY FOR DIFFERENTIATING BETWEEN BENIGN AND MALIGNANT CERVICAL LYMPH NODES?
}

\author{
Vishwanath Reddy ${ }^{1}$, Adarsh K. M², Devadasa Acharya K3, Ravichandra $G^{4}$, Vinayaka U. S5, Renuka Patil \\ 1 Postgraduate Student, Department of Radiodiagnosis, Yenepoya Medical College. \\ ${ }^{2}$ Assistant Professor, Department of Radiodiagnosis, Yenepoya Medical College. \\ 3 Professor and HOD, Department of Radiodiagnosis, Yenepoya Medical College. \\ 4 Professor, Department of Radiodiagnosis, Yenepoya Medical College. \\ ${ }^{5}$ Associate Professor, Department of Radiodiagnosis, Yenepoya Medical College. \\ ${ }^{6}$ Postgraduate Student, Department of Pathology, Yenepoya Medical College.
}

\begin{abstract}
\section{BACKGROUND}

Cervical lymphadenopathy is a very common condition being referred for evaluation in the radiology department. It is very much necessary to differentiate these cervical lymph nodes into benign and malignant which will change the course of treatment. We aimed at differentiation of the enlarged cervical lymph nodes into benign and malignant by B-mode Ultrasound and Elastography, comparing with histopathology.
\end{abstract}

\section{MATERIALS AND METHODS}

Sixty four lymph nodes from 64 patients were examined by both B-mode sonography and elastography and compared with histopathological correlation in this accuracy. On B-mode sonography, the lymph nodes were classified as malignant and benign based on their score with 8 as the cut-off (Benign $\leq 8$, Malignant $>8$ ). Scoring was based on size, shape, echogenicity, margins and hilar appearance. These lymph nodes on elastographic examination were diagnosed as benign and malignant based on the patterns of elasticity, with patterns $1 / 2 / 3$ as benign and patterns $4 / 5$ as malignant. The patterns $1,2,3$, 4, and 5 were assigned scores of 2 , 4 , 6,8 , and 10 respectively. The combined score for each lymph node was the sum of the B-mode and elastographic scores. A statistically cut-off line between metastatic and reactive was set between scores 12 and 13 . Scores 7-12 was determined to be reactive, and scores 13-20, metastatic. The final scores were compared with the histopathological findings.

\section{RESULTS}

Sensitivity, specificity and accuracy of B-mode sonography was $80 \%, 50 \%$ and $59 \%$ respectively; $86 \%, 61 \%$ and $71 \%$ for elastography; and $81 \%, 62 \%$ and $75 \%$ for the combined evaluation.

\section{CONCLUSION}

Elastography has better sensitivity, specificity and accuracy in detecting malignant cervical lymph nodes than B-mode sonography, and the combined sonographic evaluation (B-mode with elastography) improves the accuracy.

\section{KEYWORDS}

Elastography, B-Mode Sonography, Malignant Lymph Nodes.

HOW TO CITE THIS ARTICLE: Reddy V, Adarsh KM, Acharya DK, et al. Are we justified in supplementing elastography with high resolution ultrasonography for differentiating between benign and malignant cervical lymph nodes? J. Evolution Med. Dent. Sci. 2016;5(103):7534-7539, DOI: 10.14260/Jemds/2016/1706

\section{BACKGROUND \\ Elasticity is a mechanical tissue character, which restrains the movement of tissues when pressure is applied. It varies in different types of tissues (fat, collagen and so forth) and in the same tissue in different pathologic states (inflammatory, malignant). ${ }^{1}$ During the past few years, sonographic elastography, magnetic resonance elastography and some other techniques have performed digital}

Financial or Other, Competing Interest: None.

Submission 08-11-2016, Peer Review 13-12-2016,

Acceptance 19-12-2016, Published 26-12-2016.

Corresponding Author:

Dr. Vishwanath Reddy,

Post Graduate Student,

Department of Radiodiagnosis,

Yenepoya Medical College, Yenepoya University,

Deralakatte,

Mangalore-585018.

E-mail:drvishwanathreddy@gmail.com

DOI: $10.14260 /$ jemds $/ 2016 / 1706$ measurements of tissue hardness. $^{2}$ In sonographic elastography, image representation of tissue hardness can be obtained using a conventional sonography machine with special software and a conventional ultrasound probe. 3,4

Sonographic elastography has been used to examine several organs. The breast, thyroid, prostate, cervix, liver and so forth. ${ }^{5}$ The head and neck contains 60 to 70 lymph nodes of the 400 to 450 in the human body. ${ }^{6}$ Differentiation between reactive and metastatic lymphadenopathy is vital and one of the differentiating criteria is hardness (elasticity) of the lymph node.

\section{MATERIALS AND METHODS}

This was a prospective study from August to November 2016. 64 patients with cervical lymphadenopathy who were referred for sonography and ultrasound-guided fine needle aspiration cytology (FNAC) were the participants. 
After obtaining written informed consent, patients underwent B-mode sonography, elastography and ultrasoundguided FNAC.

The study was conducted at Yenepoya Medical College Hospital. Lymph nodes from 64 patients were examined by both B-mode sonography and elastography and were later compared with histopathological correlation in this study.

After obtaining written consent from the patients, scans were done with a linear transducer 11L-D (4-10 MHz) in GE Voluson E8 Machine equipped with the real-time strain elastography. One radiologist with experience in conventional sonography and a novice in elastography performed the sonography.

The participants underwent B-mode sonography followed by elastography using same probe in the supine position with extended neck using a pillow below the shoulder. In case of multiple enlarged lymph nodes in same patient, the largest lymph node was studied. In case of no discrete lymph nodes being identified, smallest possible lymph node mass was selected for the study so that we could fit the lymph node in the elastography box. The scans were completed within a period of 5 to 10 minutes depending upon the case. In the same setting, FNAC of the lymph node was done and reports were collected within a period of 1 week.

\section{B -Mode}

For each lymph node studied, B-mode images were obtained and findings were documented in the below mentioned headings. The lymph nodes were classified according to the 1997 American Joint Committee on Cancer (AJCC) criteria for lymph nodes.7,8,9

1. Size $(<1 \mathrm{~cm}-1,>1 \mathrm{~cm}-2) .{ }^{9}$

2. Longitudinal/Transverse diameter ratio $(<0.6-1$, $>0.6-2) \cdot 7,10,11$

3. Shape (Oval -1, Round, -2 ). $7,10,11$

4. Echogenicity (Homogenous -1 , Non-homogenous -2).8,12

5. Margins (Regular -1, Irregular -2).7,13

6. Hilar appearance (Present -1, Absent -2).7,14

Scores obtained by the B-mode ultrasound were summed up and the lymph nodes were classified as benign and malignant with 8 as the cut-off (Benign $\leq 8$, Malignant $>8$ ). ${ }^{5}$

\section{Strain Elastography}

For strain elastography, linear transducer was placed over the lymph node and light manual pressure was applied with the transducer with gradual decompression until a stable image was obtained. ROI (Region of interest) of the Lymph node was compared with ROI of the adjacent muscle. Surrounding tissues like bone, blood vessels were avoided. The images were analysed and the lymph nodes were classified as benign and malignant based on their colour patterns as mentioned below. Ultrasonography elastogram was displayed over the B-mode image in a colour scale comprising, red for nodes with greatest elastic strain (soft), green for intermediate and blue for nodes with no strain (hardest) as shown in Figure 2.

Elastographic patterns were determined on the distribution and percentage of the lymph node areas with high elasticity-
1. Pattern 1, absent or a very small hard area (blue area)

2. Pattern 2, blue/hard area $<45 \%$ of the ROI

3. Pattern 3 , blue/hard area $\geq 45 \%$ of the ROI

4. Pattern 4, peripheral hard/blue and central soft/red area

5. Pattern 5, hard area occupying entire lymph node with or without a soft rim. 5,6

The patterns 1, 2, 3, 4, and 5 will be assigned scores of 2, 4, 6,8 , and 10 respectively.5,6

Scores obtained by the elastography were summed up and the lymph nodes were classified as benign and malignant with 8 as the cut-off (Benign $\leq 8$, Malignant $>8)^{5}$ as shown in Table 1 and Figures 2-6.

The scores so obtained by B-mode ultrasound and Elastography were added up. A statistically supported cut-off line between metastatic and reactive was set. Scores 7-12 was determined to be reactive, and scores 13-20 Metastatic. Ultrasound-guided FNAC of all the enlarged cervical lymph nodes was performed under aseptic precaution using 21 gauge needles and sent for cytological study to the Department of Pathology (Radiological reports hidden), Yenepoya Medical College, Deralakatte. The Reports were collected within a period of 1 week to minimise errors. The final scores were compared with the histopathological findings.

\section{Combined Evaluation of the Nodes}

Combined score will be the total score of elastographic scores plus B-mode scores. A cut-off line between metastatic and reactive was set between scores 12 and 13, depending on the best accuracy. Scores 7-12 were determined to be reactive, and scores 13-20 metastatic. ${ }^{15}$

The lymph nodes were classified into benign and malignant based on the B-mode, Elastographic colour patterns and Strain ratios (Benign and malignant). The elastographic and B-mode analysis were carried out in 5 to 10 minutes time. After elastography evaluation, ultrasound-guided FNAC of all the enlarged cervical lymph nodes was performed under aseptic precaution using 21 gauge needles and sent for cytological study to the Department of Pathology (Radiological reports hidden), Yenepoya Medical College, Deralakatte. The Reports were collected within a period of 2 weeks to minimise errors.

\section{Final Diagnosis}

Lymph node was determined to be reactive or malignant on the basis of histopathology result which was our gold standard.

\section{Ethical Considerations}

In all patients, ultrasound and FNAC done on the request of their consulting physicians. Ethical clearance was obtained for the study by the ethical committee prior to the study.

\section{RESULTS}

Out of the 64 patients, 38 were male and 26 were female with a mean age of 42 years.

All the 64 patients underwent FNAC and their results are tabulated (Table 2).

\section{B-mode Sonography}

Several previous studies have been published before on diagnosis of malignant cervical lymph node by B-mode 
sonography. ${ }^{9-14}$ With short axis diameter cut-off of $10 \mathrm{~mm}, 20$ of 64 lymph nodes were labelled as malignant (38 were actually malignant on HPE). Sensitivity and specificity of $71 \%$ and $50 \%$ noted respectively with insignificant p-value $(0.08)$, whereas in a study by Lyschick et al 7 using a cut-off diameter of $8 \mathrm{~mm}$ the accuracy was $65 \%$, seen to be slightly better when smaller sizes were used.

With the size/length ratio cut-off of $0.6,24$ of 64 lymph nodes were called as malignant. Sensitivity and specificity of $75 \%$ and $56 \%$ respectively with a significant p-value $(0.011)$ was similar to previous studies supporting the round shape for malignant nodes.7,10,11 Irregularity of margins in the lymph nodes as a criteria for malignancy had a poor sensitivity and specificity in our study. All the 64 lymph nodes examined showed absence of hila. But HPE showed $41 \%$ of these lymph nodes to be benign. Hence, the specificity of B-mode sonography was found to be less in this criterion. Heterogenous lymph nodes on B-mode were considered malignant in our study. With this criterion, we labelled 30 out of 38 lymph nodes as malignant with the sensitivity of $71 \%$ specificity of $63 \%$ and p-value being significant (0.007) as shown in Table 3.

With B-mode ultrasonography cut-off score of 8, we found sensitivity of $80 \%$, specificity of $50 \%$ and NPV of $84 \%$. P-value with this cut-off score was found to be significant $(0.024)$ as shown in Table 5.

\section{Elastography}

With patterns 3,4 and 5 considered as malignant, we found accuracy of $71 \%$ with sensitivity of $86 \%$ and specificity of $61 \%$. The p-value of this was statistically significant $(0.004)$ (Table 4 and Table 5), as compared to other studies as Lyshick et al7, Alam et al 15 which had sensitivities of $85 \%$ and $83 \%$, specificities of $98 \%$ and 100 , accuracies of $92 \%$ and $89 \%$ respectively.

\section{Combined Assessment}

Elastography and B-mode sonography score were added up and a cut-off of 12 was set for benign nodes. With this criteria we achieved a sensitivity of $81 \%$ and specificity of $62 \%$ with a PPV of $68 \%$ and NPV $76 \%$. The p-value for this cut-off was also significant (0.012).

\section{Diagnostic Performance}

The diagnostic performance of B-mode sonography, elastography and combined evaluation are shown in Table 5.

\begin{tabular}{|c|c|c|c|}
\hline Pattern & Score & Description & Elastography \\
\hline 1 & 2 & $\begin{array}{c}\text { Absent or very small } \\
\text { blue areas }\end{array}$ & Reactive \\
\hline 2 & 4 & $\begin{array}{c}\text { Small scattered blue } \\
\text { areas ,total blue area } \\
<45 \%\end{array}$ & Reactive \\
\hline 3 & 6 & $\begin{array}{c}\text { Large blue area ,total } \\
\text { blue area } \geq 45 \%\end{array}$ & Reactive \\
\hline 4 & 8 & $\begin{array}{c}\text { Peripheral blue area } \\
\text { and central green } \\
\text { area, suggesting } \\
\text { central necrosis }\end{array}$ & Malignant \\
\hline 5 & 10 & $\begin{array}{c}\text { Blue area with or } \\
\text { without a green rim }\end{array}$ & Malignant \\
\hline \multicolumn{5}{|c|}{ Table 1. Pattern and Scoring of Elastography Findings } \\
\hline
\end{tabular}

\begin{tabular}{|c|c|}
\hline Type & No \\
\hline Benign & 28 \\
\hline Tubercular & 4 \\
\hline Non-Granulomatous & 24 \\
\hline Total & $\mathbf{2 8}$ \\
\hline Malignant & 36 \\
\hline Thyroid & 18 \\
\hline Larynx & 12 \\
\hline Lung & 2 \\
\hline Breast & 8 \\
\hline Others & $\mathbf{3 6}$ \\
\hline Total & \\
\hline $\begin{array}{c}\text { Table 2. Total Number of Benign and Malignant Lymph } \\
\text { Node on Histopathology Evaluation }\end{array}$ \\
\hline
\end{tabular}

\begin{tabular}{|c|c|c|c|c|}
\hline $\begin{array}{c}\text { Sonographic } \\
\text { Criteria }\end{array}$ & Lymph & Nodes & $\begin{array}{c}\text { Accuracy } \\
(\%)\end{array}$ & $\begin{array}{c}\text { P- } \\
\text { value }\end{array}$ \\
\hline & $\begin{array}{c}\text { Reactive } \\
(\%)\end{array}$ & $\begin{array}{c}\text { Metastatic } \\
(\%)\end{array}$ & & \\
\hline \multicolumn{5}{|l|}{ B-mode } \\
\hline $\begin{array}{c}\text { Short axis } \\
\text { diameter }\end{array}$ & & & 59 & 0.08 \\
\hline$\leq 1 \mathrm{~cm}$ & $18(50)$ & $18(50)$ & & \\
\hline$\geq 1 \mathrm{~cm}$ & $8(28)$ & $20(71)$ & & \\
\hline S/L ratio & & & 65 & 0.011 \\
\hline$\leq 0.6 \mathrm{~mm}$ & $18(56)$ & $14(43.8)$ & & \\
\hline$\geq 0.6 \mathrm{~mm}$ & $8(25)$ & $24(75)$ & & \\
\hline Margin & & & 53 & 0.029 \\
\hline Regular & $22(44)$ & $28(56)$ & & \\
\hline Irregular & $4(27)$ & $10(71)$ & & \\
\hline \multicolumn{5}{|l|}{ Hilum } \\
\hline Present & 0 & 0 & & \\
\hline Absent & $26(41)$ & 38 (59) & & \\
\hline Echogenicity & & & 53 & 0.007 \\
\hline Homogenous & $14(63)$ & $8(36)$ & & \\
\hline Heterogenous & $12(28)$ & $30(71)$ & & \\
\hline Table 3. Res & s Based & B-Mode C & eria fo & ign \\
\hline
\end{tabular}

\begin{tabular}{|c|c|c|}
\hline Total = 64 & & \\
\hline Elastography & Benign & Malignant \\
\hline 1 & 10 & 4 \\
\hline 2 & 16 & 8 \\
\hline 3 & 0 & 20 \\
\hline 4 & 2 & 4 \\
\hline Table 4. Results Based on Elastographic Criteria for \\
Benign and Malignant Lymph Nodes \\
\hline
\end{tabular}

\begin{tabular}{|c|c|c|c|}
\hline $\begin{array}{c}\text { Diagnostic } \\
\text { Performance }\end{array}$ & $\begin{array}{c}\text { B- } \\
\text { Mode } \\
\text { Score }\end{array}$ & Elastography & $\begin{array}{c}\text { Combined } \\
\text { Score }\end{array}$ \\
\hline Sensitivity (\%) & 80 & 86 & 81 \\
Specificity (\%) & 50 & 61 & 62 \\
Accuracy (\%) & 59 & 71 & 75 \\
PPV & 42 & 68 & 68 \\
NPV & 84 & 84 & 76 \\
p-value & 0.024 & 0.004 & 0.012 \\
\hline \multicolumn{3}{|c|}{ Table 5. Results of Diagnostic Capability of B-mode } \\
Sonography, Elastography, Combined Methods \\
\hline
\end{tabular}





Figure 1. Elastography examination of level IV lymph node in a 50-year-old man. Elastogram appears on right of the box and is superimposed on a corresponding $B$-mode image. $B$-mode mage is displayed on the left side of monitor, Colour scale of tissue elasticity and frequency scale appear on the left upper and lower respectively. Final diagnosis was metastasis.

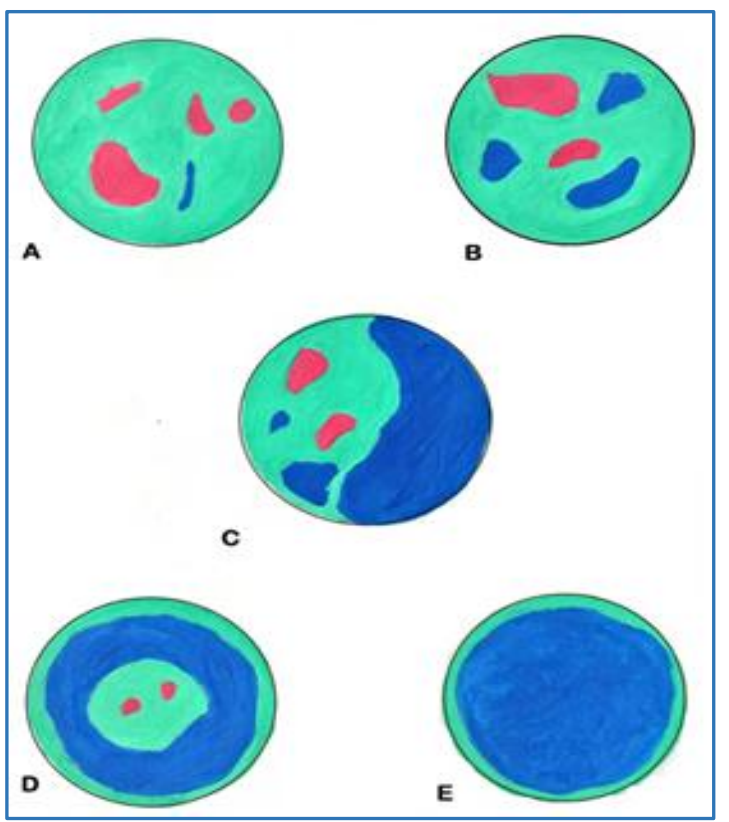

Figure 2. Diagrammatic appearance of five patterns of lymph nodes on Elastography

A. Pattern 1: Absent or a very small hard area (blue area).

B. Pattern 2: Blue/hard area $<45 \%$ of the ROI.

C. Pattern 3: Hard area $\geq 45 \%$ blue/hard area $\geq 45 \%$ of the ROI.

D. Pattern 4: Peripheral hard/blue and central soft/red area.

E. Pattern 5: Hard area occupying entire lymph node with or without a soft rim.
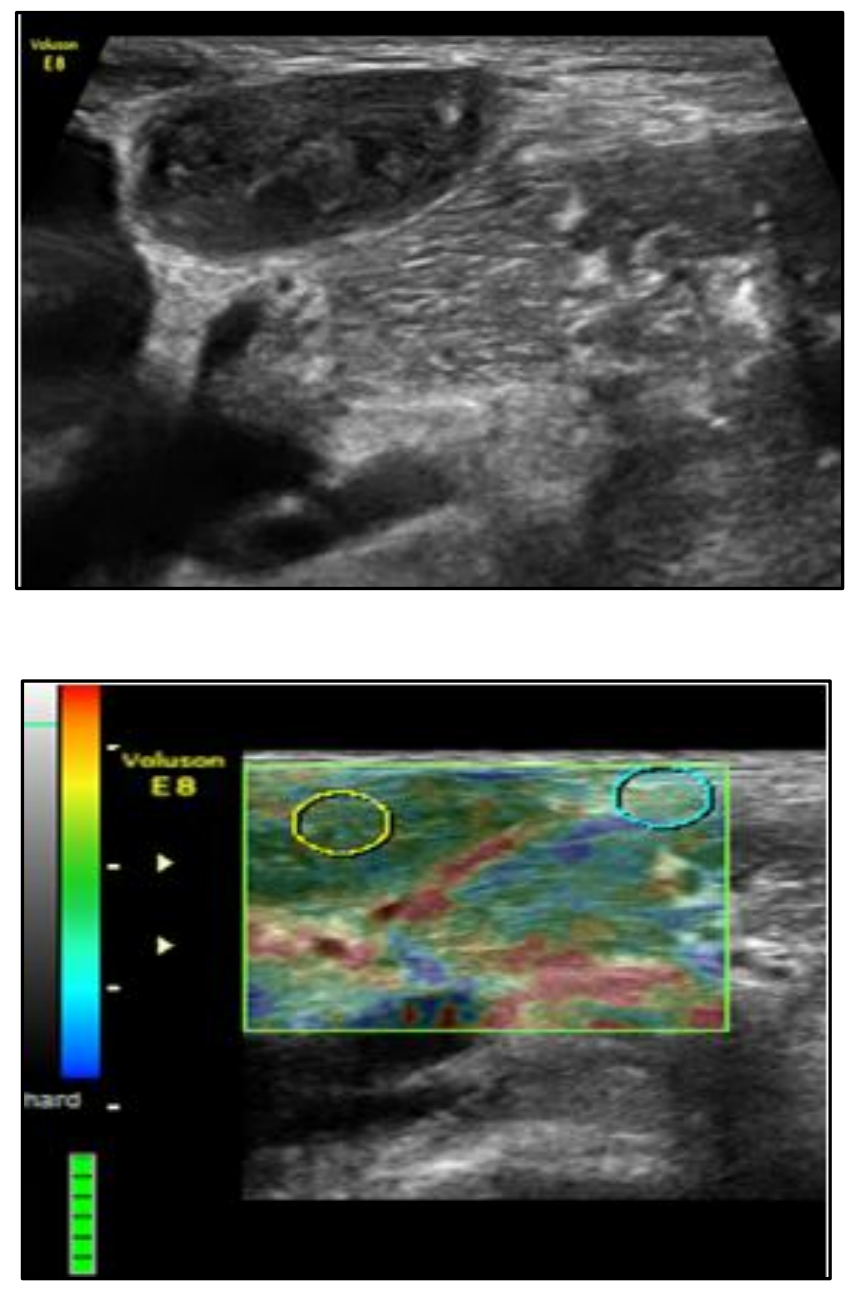

Figure 3. Transverse sonogram of level V cervical lymph node in a 20-year-old man, B-mode on left shows score of 7, Elastography on left shows pattern 1 (score 2) benign lymph node.








Figure 4. (a) Transverse sonogram of left level II cervical lymph node in a 53-year-old man, B-mode on the left showed score of 4, (b)Elastography showed pattern 2 (score 4) suggestive of benign lymph node.



Figure 5. (a) Transverse sonogram of right level IV cervical lymph node in a 53-year-old man, B-mode sonography on the left showed B-mode score of 8 , Elastography on the right showed pattern 3 (score 6).

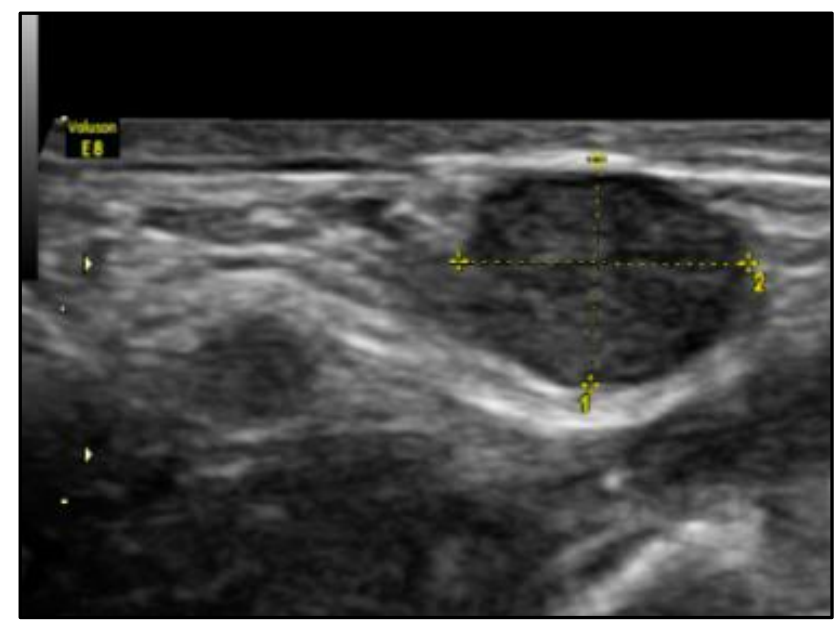

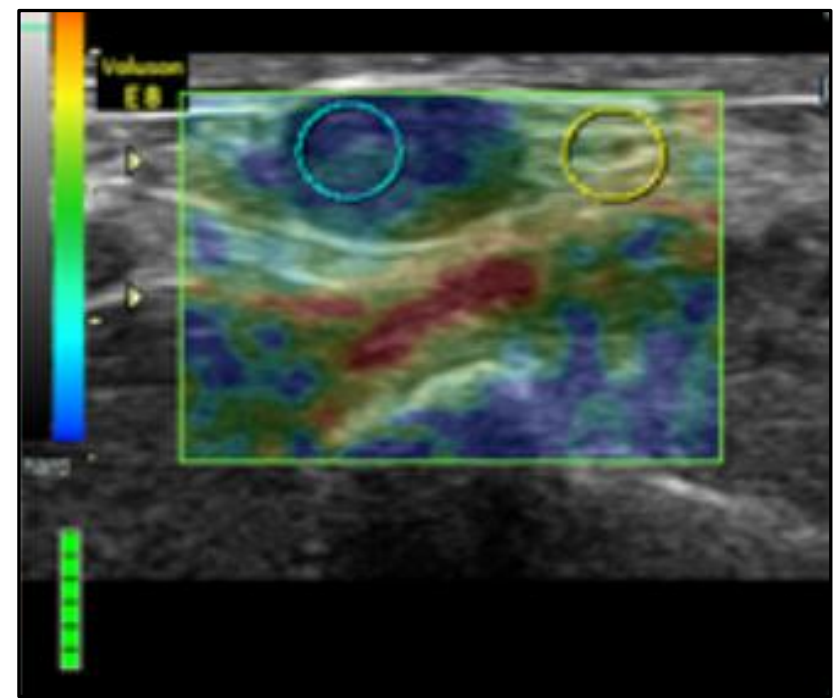

Figure 6. (a)Transverse B-mode sonogram of left level III cervical lymph node of a 55-year-old man showed score of 7, (b) Elastography showed pattern 4 (score 8).

Final HPE result was metastatic carcinoma from supraglottis

\section{DISCUSSION}

In this study, we have documented the accuracy of sonography and elastography individually and combined method in the differential diagnosis of benign versus malignant cervical lymph node.

\section{B-Mode Sonography}

Several previous studies have been published before on diagnosis of malignant cervical lymph node by B-mode sonography. ${ }^{9-14}$ The accuracy of short axis diameter in our study was $59 \%$ and $p$ value of 0.08 using cut-off diameter of 1 $\mathrm{cm}$, whereas in a study by Lyschick et $\mathrm{al}^{7}$ using a cut-off diameter of $8 \mathrm{~mm}$ the accuracy was $65 \%$, seen to be slightly better when smaller sizes were used.

The S/L Ratio of $\leq 0.6 \mathrm{~mm}$ for benign nodes had accuracy of $65 \%, \mathrm{p}$ value of 0.011 was similar to previous studies supporting the round shape for malignant nodes.7,10,11

Irregularity of margins in the lymph nodes as criteria for malignancy had a poor sensitivity and specificity in our study. In our study, the accuracy of lymph node margin as criteria to diagnose benign and malignant nodes was only about 53\% with insignificant $p$ value, suggesting that margins were no longer useful criteria. In our study, all the 64 LNs had absent hilum among which 26 lymph nodes (41\%) were benign and 38 (59\%) were malignant so the statistical data could not be calculated for this criterion.

Irregular margins of the lymph nodes and absence of hila as criteria for malignancy were found to be of no statistical significance in our study. Size of the lymph nodes more than 1 $\mathrm{cm}, \mathrm{S} / \mathrm{L}$ ratio of $0.6 \mathrm{~cm}$, rounded lymph nodes and heterogeneity of the lymph nodes as criteria for malignant lymph nodes were statistically significant ( $p$ value $<0.005$ ).

Overall B-mode sonography had a sensitivity of $80 \%$ and specificity of $50 \%$. 


\section{Elastography}

Our study showed strain elastography had a sensitivity of $86 \%$, specificity $61 \%$, accuracy of $71 \%$ in diagnosing malignant lymph nodes as compared to other studies as Lyshick et al,7 Alam et al ${ }^{15}$ which had sensitivities of $85 \%$ and $83 \%$, specificities of $98 \%$ and 100 , accuracies of $92 \%$ and $89 \%$ respectively using both qualitative and quantitative criteria. Elastography had a better sensitivity and specificity than Bmode sonography.

\section{Combined Evaluation}

The accuracy and specificity of the combined evaluation was slightly higher than that of individual evaluations $75 \%$ and $62 \%$ respectively, suggesting that elastography can be added to B-mode sonography which will enhance the overall accuracy in diagnosing malignant lymph nodes.

Elastography and combined method provides better sensitivity and specificity than B-mode sonography alone. Elastography increases the accuracy of sonography in differentiating benign vs. malignant nodes.

\section{Limitations}

The study had some limitations.

1. Our data sample was small.

2. We compared lymph nodes from different regions of neck.

3. In case of no discrete lymph node, we used smallest lymph nodal mass for which no previous studies were available.

4. We used strain elastography for which the pressure was not defined and was subjective which would have led to alteration of the patterns with different radiologists.

5. Strain elastography is a less sensitive tool than shear wave elastography.

6. The study could not differentiate subtypes of benign and malignant lymph nodes (Differentiate reactive adenitis versus TB adenitis, Metastatic adenopathy versus Lymphoma).

\section{CONCLUSION}

Our study showed elastography has better sensitivity, specificity and accuracy in detecting malignant cervical lymph nodes than B-mode sonography and the combined sonographic evaluation improves the accuracy.

\section{REFERENCES}

1. Okasha HH, Mansour M, Attia KA, et al. Role of high resolution ultrasound/endosonography and elastography in predicting lymph node malignancy. Endoscopic Ultrasound 2014;3(1):58-62.
2. Huwart L, Peeters F, Sinkus R, et al. Liver fibrosis: noninvasive assessment with MR elastography. NMR Biomedicine 2006;19(2):173-9.

3. Ophir J, Cespedes I, Ponnekanti H, et al. Elastography: a quantitative method for imaging the elasticity of biological tissues. Ultrasonic Imaging 1991;13(2):111-34.

4. Ophir J, Garra B, Kallel F, et al. Elastographic imaging. Ultrasound Med Biol 2000;26(Suppl 1):S23-9.

5. Alam F, Naito K, Horiguchi J, et al. Accuracy of sonographic elastography in the differential diagnosis of enlarged cervical lymph nodes: comparison with conventional Bmode sonography. American Journal of Roentgenology 2008;191(2):604-10.

6. Bhatia KS, Lee YY, Yuen EH, et al. Ultrasound elastography in the head and neck. Part I. Basic principles and practical aspects. Cancer Imaging 2013;13(2):253-9.

7. Lyshchik A, Higashi T, Asato R, et al. Cervical lymph node metastases: diagnosis at sonoelastography-initial experience. Radiology 2007;243(1):258-67.

8. Dudea SM, Botar-Jid C, Dumitriu D, et al. Differentiating benign from malignant superficial lymph nodes with sonoelastography. Medical Ultrasonography 2013;15(2):132-9.

9. Castelins JA, van den Brekel MW, Mukherji SK, et al. Ultrasound of the neck. In: Som PM, Curtin HD. eds. Head and neck imaging. Boston, MA: Mosby 2003:1935-53.

10. Vassallo P, Wernecke K, Roos N, et al. Differentiation of benign from malignant superficial lymphadenopathy: the role of high-resolution US. Radiology 1992;183(1):215-20.

11. Takashima S, Sone S, Nomura N, et al. Nonpalpable lymph nodes of the neck: assessment with US and US-guided fineneedle aspiration biopsy. Journal of Clinical Ultrasound 1997;25(6):283-92.

12. Ying M, Ahuja A, Metreweli C. Diagnostic accuracy of sonographic criteria for evaluation of cervical lymphadenopathy. Journal of Ultrasound in Medicine 1998;17(7):437-45.

13. Ahuja A, Ying M. An overview of neck node sonography. Investigative Radiology 2002;37(6):333-42.

14. Leboulleux S, Girard E, Rose M, et al. Ultrasound criteria of malignancy for cervical lymph nodes in patients followed up for differentiated thyroid cancer. The Journal of Clinical Endocrinology \& Metabolism 2007;92(9):3590-4. 